\title{
Ana Castaño
}

Seminario de Poética, IIFL, UNAM

\section{El sermón en España durante los siglos XV y XVI (algunos rasgos del género)}

Hace ya varios años, cuando empecé a leer comentarios sobre poesía escritos en castellano durante la Edad Media y el Siglo de Oro, me llamaron la atención algunos rasgos retóricos y estilísticos que parecían no encajar del todo en la idea que yo tenía de esas obras tan vituperadas y tan incomprendidas, cuando no del todo ignoradas. Esa idea era, en términos muy generales, la siguiente: los comentarios fueron obras producidas en exquisitas torres de marfil, en casi total aislamiento, y destinadas a una lectura igualmente aislada y silenciosa; por tanto, obras que en ningún momento pasaron por la voz viva, sino que desde siempre pertenecieron de lleno al reino de lo escrito, de lo académico y lo culto por excelencia. Según esta idea, y como consecuencia de lo anterior, los comentarios debían ser también ajenos en todo a los hechos de la vida cotidiana, sordos al lenguaje, a las expresiones, a la cultura y al humor de tipo popular, Además, como deudores que fueron de índices y Polianteas, tablas de concordancias y lugares comunes, su destino, también casi desde un principio, parecía inevitable: convertirse ellos mismos en obras de consulta, una especie de diccionarios de "lugares" y tópicos literarios clásicos, o bien de primitivas concordancias de la obra de ciertos autores. Es decir, los comentarios de poesía serían obras que poquísimos lectores 
leerían de principio a fin por simple gusto, y a las que se recurriría únicamente para aclarar pasajes o alusiones difíciles, o para esclarecer determinadas fuentes literarias. Y ciertamente, esta idea de lo que fueron y siguen siendo esas obras para nosotros tiene su dosis de verdad; sin embargo, el comentario es mucho más que eso. Se trata de un género que tuvo significativas repercusiones en el desarrollo de la crítica literaria, en el género del ensayo y, en general, en la manera que tenemos hoy de enfrentarnos a los textos literarios, tanto desde el lado de la recepción como del de la creación.

Si el comentario de poesía tuvo esas repercusiones, ello se debió en buena medida precisamente a que no se limitó a la torre de marfil, sino que salió a las calles y circuló manuscrito o impreso (sólo o acompañando la obra comentada), si bien no entre el "gran público" al menos entre un público de aficionados bastante más extenso de lo que se ha querido suponer. Además los comentarios eran, en diversas ocasiones, leídos en voz alta en reuniones, tertulias y academias que algunas veces eran abiertas al público. Por otra parte, aunque en ellos se recoge ante todo la tradición culta y la palabra escrita de las "autoridades", también nos brindan una cantidad considerable de "voces de la calle": no sólo palabras, chistes, expresiones populares, refranes, etc. sino datos sobre hechos de la vida cotidiana, privada y pública, de aquel entonces.

Hay, así, dos vertientes que confluyen en el género del comentario: la de la tradición escrita, culta y erudita, por una parte, que rastrea hasta la más libresca antigüedad clásica motivos literarios y usos lingüísticos, citas literales y alusiones (mitológicas, históricas, geográficas); y la de una tradición más cercana a la oralidad, por la otra, si no propiamente popular sí dirigida a sectores amplios de la sociedad y por tanto en lengua vernácula. A esta segunda vertiente debe el comentario ese tono desenfadado e informal - hoy diríamos que de "divulgación"- ese interés por la realidad inmediata que continua- 
mente asoma entre sus páginas y que presupone un oyente, $0 \mathrm{al}$ menos un lector muy vivo y cercano.

$Y$ precisamente en esa confluencia de vertientes se abre ante nuestros ojos el importante cauce literario del que forman parte tanto el género del comentario como ese otro género con el que guarda estrecha afinidad: el sermón; ambos comparten varios rasgos formales. En las notas que siguen me referiré a algunos de ellos. ${ }^{1}$

En primer lugar, decíamos que el sermón paticipa también de ambas tradiciones: la de la escritura y la antiguedad clásica y la de la oralidad y las lenguas vivas, vernáculas. Recordaremos aquí un hecho simbólico que Francisco Rico $(1977,6)$ subraya justamente para ilustrar cómo "se cruzaban en época tempranísima la tradición homilética y la lengua vulgar": al margen de unos sermones de San Agustín (escritos naturalmente en latín) aparece el primer testimonio escrito de nuestra lengua: las glosas emilianenses. Y es un hecho que, a lo largo de su historia, el sermón supo combinar, por una parte, una tradición culta (en la que se mezclaban la exégesis bíblica patrística, la antigua retórica y las técnicas de la escolástica; y que cristalizó en la utilización de una estructura artística muy precisa y elaborada); $y$, por la otra, una dimensión popular que conllevaba un sello de oralidad y que resultaba indispensable si habían de llevarse a cabo eficazmente los fines doctrinales y catequéticos que la Iglesia se proponía. ${ }^{2}$

Lo anterior podría decirse igualmente del comentario, que proviene de una fuerte tradición culta constituida por casi las

${ }^{1}$ Puesto que en otros trabajos he señalado la presencia de estos rasgos en el comentario, aquí traeré únicamente algunos ejemplos de su presencia en el sermón, entendiendo que en todos los casos pueden encontrarse ejemplos equivalentes en comentarios de la época.

2 Rico $(1977,10)$ señala el papel que desempeñó el brote de las órdenes mendicantes en esta especie de popularización del sermón, cuando los predicadores salieron a las calles a buscar su nuevo público, lo que necesariamente le imprimí́ al género una lengua y un nivel distintos, haciendo por ejemplo que la vida cotidiana "irrumpiera en los púlpitos". 
mismas corrientes que la tradición del sermón, sólo que su estructura no es, como la de éste, fija ni elaborada sino variable y en extremo sencilla, pues se limita a seguir verso por verso el poema comentado. Por otra parte, la finalidad primaria del comentario no es precisamente catequética ni doctrinal sino pedagógica y de divulgación de valores y cánones literarios y culturales; sin embargo ambos, el comentario y el sermón, recurren continuamente a un tono directo, a una especie de oralidad que refleja, y al mismo tiempo busca, el contacto con un público oyente (ya sea en la iglesia o en las tertulias y academias públicas).

A ese tono personal contribuyen las frecuentes "interrupciones" en el discurso del sermón (y por supuesto en el del comentario) que simulan $\longrightarrow$ adelantan — las preguntas u objeciones que podría formular algún oyente. Como cuando Fray Hortensio Paravicino discurre en su Sermón de Santa Isabel (1625) sobre el hecho de que la santa renunció a ser reina de Portugal para convertirse en monja y ser así verdadera Reina, y se détiene para poner él mismo en boca de sus oyentes una hipotética objeción a su uso de la retórica: "Diréisme, empero, que ésta es paradoja, como otras mías...” (Paravicino, 167). A veces el predicador interpela francamente a sus oyentes para zanjar con energía una hipotética discusión: "No me preguntéis nada, que yo no sé, ni puedo deciros más de lo que os digo". (Paravicino, "Oración fúnebre de Sor Margarita de la Cruz", 333). O cuando Ormaza quiere explicar las causas de la muerte de la Virgen y primero descarta las que el sentido común argüiría (la enfermedad o bien "la recíproca pelea del calor y húmedo"), ${ }^{3}$ para concluir así: "Ea, que no ai que dudar: de amor murió María señora nuestra".

${ }^{3} \mathrm{Y}$ al descartarlas aduce conocimientos "actualizados" de medicina: “...en el perfecto temperamento deste Sagrado Cuerpo no cabían assechancas de enfermedad alguna; y la recíproca pelea del calor y el húmedo, conjurados en su acabamiento, no es para los Filósophos modernos tan cierta como los antiguos pen- 
En el segundo ejemplo estamos quizá más cerca del procedimiento escolástico de la quaestio (en la explicación de las Escrituras, consistía en hacerse constantemente preguntas por lo regular "bizantinas"), utilizado ampliamente por ambos géneros durante varios siglos. Un ejemplo de esa quaestio escolástica reutilizada por Paravicino (Sermón de la Presentación de Nuestra Señora al Templo, 1616): “ipor qué, para formar un sexo frágil [Eva] de otro más fuerte [Adán] no escogió Dios la carne del lado, más que la costilla?" (56). Tan utilizado seguía siendo este procedimiento que Ormaza, en 1648, repetidas veces se refiere con impaciencia a esos predicadores que "gustan de preguntar" prolija y artificialmente: "entra el porqué a dozenas y mui falso se haze de rogar para lo que desea dezir, y quizá nadie tiene curiosidad de saberlo. Parece preguntan cosicosas a niños a quienes con el arte de escasear se haze estimar la solución" (68).

Y no obstante, además de esta fundamental impronta de las técnicas escolásticas para discurrir sobre los textos, desde muy temprano el sermón y el comentario incorporaron a su discurso ese otro tipo de preguntas a que acabamos de referirnos, más naturales y "dialógicas", que reflejaban la presencia clara de un oyente o, en el último de los casos, de un lector bastante inmediato. Un ejemplo de San Vicente Ferrer (principios del siglo $\mathrm{xv}$ ):

Mas dirán agora aquí los jodíos: "-Si Dios dio la ley de Moysés, avemos a dezir que buena ley es, pues que él la dio [...] Pues si aquélla es buena ley, ¿por qué quiso después dar otra?...

Ascuchad respuesta. Di, jodío, ¿la noche quién la fizo, sinon Dios? Pues si Dios la fizo buena es e complida [...] ¿Pues por qué fizo después venir el día claro, ca Dios non se muda?... (Cátedra: 1994, 387)

saron, a lo menos no es tan irreparable a quien conozca las calidades del alimento" (204). 
Este tipo de preguntas y hasta de diálogos, mucho más vivos y espontáneos que la quaestio escolástica, responden desde luego a situaciones comunicativas también más reales, vivas y espontáneas que las que se daban en la exégesis bíblica patrística. Así, no faltan desde muy temprano anécdotas de intervenciones reales de uno o más oyentes (sobre todo del gremio eclesiástico), para aclarar o "corregir" algún punto doctrinal en medio de un sermón. ${ }^{4}$ Por otra parte, contamos con abundantes testimonios de las reacciones de los poetas y hombres de letras al estilo de determinados predicadores. Góngora en sus cartas les da a sus amigos noticias sobre los sermones que ha escuchado y hasta les pide copia de alguno. "Copias de sermones, como de sonetos!", exclama Dámaso Alonso, a quien debemos esta noticia sobre lo extendida que estaba la práctica de criticar a los predicadores, no sólo entre literatos sino entre el público en general, "con escándalo a veces de las personas piadosas", ya que muchos iban al sermón, según testimonios de la época, "con espíritu de curiosidad, no haciendo oficio de oyentes humildes, sino de censores y oidores rigurosos; ya condenan, ya aprueban el predicador en lo que va diciendo con arquear las cejas, torcer el rostro, dar de codo al que está al lado." (1962, 97-98). ${ }^{5}$

4 Por ejemplo la del siglo xiIs recogida y editada por A Lecoy de la Marche y Jacques Berlioz $(1992,63)$ donde se cuenta que, predicando ante el rey Luis de Francia, un cura dijo que, en el momento de la Pasión, todos los apóstoles abandonaron a Jesucristo. Al oír sus palabras, otro clérigo de rango mayor se puso de pie para reprenderlo, diciéndole que nunca debía afirmar más que lo que estaba escrito, ya que los apóstoles en efecto habían abandonado a Cristo, pero sólo de cuerpo y no de corazón. El pobre predicador iba a tener que retractarse en plena cátedra cuando el rey, levantándose a su vez, intervino para decir que la proposición del cura no era falsa, ya que estaba escrita en los Padres, y pidio que le trajeran el libro de San Agustín. Se apresuraron a obedecer y, cuando lo trajeron, para vergüenza del malhadado clérigo que había internmpido el sermón, el rey localizó un pasaje del Comentario al Evangelio de san Juan que reza así: Fugerunt, relicto eo corde et corpore ("Huyeron, abandonándolo de cuerpo y de corazón").

5 También los poetas del xvil nos han hecho llegar, a través de numerosos sonetos satíricos, la imagen festiva de esos "predicadores ensonetados". He aquí uno 
Estas circunstancias comunicativas, sociales y culturales, pueden explicar en parte otros rasgos, también característicos del sermón y del comentario, relacionados, a mi modo de ver, con esa intención de hacer participar del discurso al mayor número posible de oyentes o lectores. Uno de estos rasgos es sin duda la tensión entre la necesidad de manejar abundantes "autoridades" y la necesidad de prescindir de ellas. Por una parte, el profesional de la predicación -0 el hombre de letras que escribía un comentario de poesía en romance- tenía que hacer una exhibición de "credenciales" para granjearse el respeto y el reconocimiento de la sociedad, y por la otra tenía que ser accesible y ameno al gran público; huir la pedantería y al mismo tiempo decir cosas interesantes de manera clara y persuasiva (y, en la época barroca, hasta lucir especialmente su personal manejo de la palabra). Este conflicto se ve reflejado a cada paso en los sermones y en las "artes de predicar": José de Ormaza declara que no es de los que citan autoridades a cada paso porque sabe lo fácil que es "espantar el vulgo a citas", y se da cuenta de que los que saben no tienen necesidad de ellas para reconocer si lo que se dice está fundamentado. Y sin embargo... "por condescender con el tiempo" y protegerse de los ataques "de algún ignorante severo", anuncia que se prevendrá —en cierta ocasión — con la autoridad de San Agustín (56). ${ }^{6}$

del conde de Salinas, precisamente contra fray Hortensio Paravicino: “iOh cuánto bien, oh cuánto cultamente/ (si culto llaman lo que no se alcanza)/ critiquizó Hortensio la alabanza/ del cuanto más oculto más patente!/ Aturdió con sus términos la gente, / desempreñó de muchos la esperanza, y obró su cultivez tanta mudanza/ que arabigó todo cristiano oyente./ Velada le fue a oír, ya es religioso;/ Alcañices también, ya es varón justo;/ monjas y damas se han hortensizado;/ habla hebraísmos ya todo curioso./ Salíme yo (que tengo muy mal gusto)/ con pedazos de luz aporreado." (Alonso: 1962, 103)

${ }^{6}$ Es claro el desprecio de Ormaza hacia los que abusan de las autoridades: "muchos libros que oy vemos, donde no son autores los que assí se apellidan, sino sastres que zurzen cuanto han sisado a los vestidos ajenos. Sean pues éstos como tenderos públicos adonde se acuda por lo que sea necesario..." (56); y más adelante, como quien lo ha experimentado en carne propia, nos pone en guardia contra el peligro de engolosinarse citando a los "autores": “...esta landre de los lugares es un 
A veces (la mayoría) el conflicto frente al manejo de las autoridades cristaliza en expresiones tópicas, como cuando Paravicino exclama: " $¡ O$ Ch cuántos lugares pudiera traer de Tertuliano, de Niseno, de Gregorio! Corrija el seso la sed y mortifiquemos la erudición con ponderar uno sólo..." (27), "Oh, si no fuera tan tarde, cómo ilustrara esta verdad" (185). En otro lugar nos dice que va a omitir muchas cosas porque el sermón se está alargando: "más cuidadoso de que voy largo que ambicioso de parecer erudito" (186); o bien se elaboran refinadas estrategias para introducir las citas, o para engastar lucidamente las propias aportaciones: Dios, piensa Paravicino, a pesar de ser impecable, puesto que es creador del hombre y éste pecó, hubo de tener dolor. Pero, para "firmar" esta reflexión propia, el predicador hace como que atribuye, caballerosamente, la idea a Tertuliano, a la vez que nos hace saber que es muy suya: “...hondo pensar de Tertuliano, de Tertuliano digo, aunque lo ha sido mío, porque habiéndomela ocasionado sus palabras, no le creo a mi rudeza sentencia tanta" (179-80).

Como contraparte de la profusión de citas de autoridades clásicas (prácticamente todas en latín, a veces acompañadas de la traducción), ${ }^{7}$ los predicadores - y los comentaristas- vuelven los ojos a la realidad circundante y no escatiman alusiones a la situación social y política del momento. Recurren también con mucha frecuencia a imágenes de la vida cotidiana, llegando incluso a dar consejos prácticos a sus oyentes y lectores. En su "Sermón del 'Paternoster' ", a propósito de la cuarta petición ("Danos hoy nuestro pan de cada día"), San Vicente

género de começón que, en començando a hormiguear, apenas ai quien pueda quietar sus uñas. Un lugar despierta el picante de otro, y assí se van llamando y lisongeando el pensamiento con aires de agudeza, con tan secreta maña que mal se puede cautelar su daño. Aun toda mi ojeriza no basta, a veces, para ojear estas moscas" (81).

7 Ormaza admite que se añada al discurso "su poco de enudición [en latín]" pero, curiosamente, recomienda que "si el Auditorio fuera todo de Letrados, no se avian de dezir en Latin essas palabras, sino aludir a ellas en el romance" (198). 
Ferrer reflexiona sobre el mal hábito que muchos tienen de tragar la comida sin antes masticarla bien, lo que ocasiona problemas de digestión y hasta enfermedades graves: "E por esto -concluye-, buena gente, mazcad bien la vianda" (361). Con la sensibilidad abierta a las cosas domésticas, predicadores y comentaristas dejan pasar aquí y allá bonitos atisbos de lo que era la lengua de andar por casa: palabras humildes, pertenecientes al caló, expresiones coloquiales, refranes, onomatopeyas; muchas veces estas voces aparecen en los similes o en los exempla que forman parte de los sermones. En San Vicente Ferrer encontramos que si alguien quiere pedirle a la Virgen -que es fuente de gracia - algún favor especial, ha de acudir a ella; pero debe inclinarse porque, como bien sabemos, cuando alguna mujer va por agua a la fuente conviene que, si quiere llenar su cántaro, lo incline: "e inclinándose el cántaro, sale dél el viento, quando dize: (“Bon, bon!', e fínchese de agua." (371) En la "Oración fúnebre de Sor Margarita de la Cruz", de Paravicino vemos a María Magdalena, en la mañana de la Resurección, preguntando a los ángeles por Jesucristo y dejándolos "como dice nuestra lengua, con la palabra... en la boca" cuando lo sintió acercarse. A veces, estas voces caseras están matizadas con algo de reticencia; por ejemplo, el predicador nos dice que, a pesar de ser infanta de Austria y haber podido convertirse en reina de España, Sor Margarita decidió hacerse monja en el convento de las Descalzas donde, sin ningún tipo de privilegios, hacía hasta los más humildes trabajos domésticos: “...veréis a la infanta de Alemania, a la reina que no quiso ser vuestra, con un (¿he de disculparlo también?, tớmale en las manos Margarita y ¿no pondré yo en él la boca?) con un estropajo, digo, fregando platos." (317)

No hay que olvidar que si todas estas voces de la calle están allí, en los sermones y comentarios de poesía que nos han llegado y al lado de las palabras más consagradas de las autoridades clásicas, ello se debe a que los autores tenían una muy des- 
pierta conciencia del valor y de la dignidad de la lengua romance . Y ésta es una fuerte corriente ideológica que comparten también ambos géneros, por encima de la amplia gama de estilos literarios: la de la "ilustración y defensa de la lengua". Nuestra lengua es tan capaz de elegancia como la latina, pero nadie estima lo de casa, dice Ormaza (50); y el muy barroco Paravicino, que había introducido novedades formales en la oratoria sagrada ${ }^{8}$ se muestra francamente orgulloso de ello y exhorta a los escritores a arriesgarse y buscar nuevas formas, como hizo Colón (con quien tácitamente se compara), que no actuó por temeridad ni soberbia sino por curiosidad y ánimo, porque "Haber hallado, después de tantos, algo nuevo en esta lengua (...) no es formar otro idioma, sino venerar tanto el vulgar castellano nuestro, que nos prometemos de él la sublimidad clásica de los otros." (224) ${ }^{9}$

Hay varios otros rasgos que comparten el predicador y el comentarista en los que ya no voy a detenerme; entre ellos está una aguda conciencia de sus propios métodos exegéticos, que casi siempre van haciendo explícitos en diversos puntos de su discurso. Propongo un análisis cuidadoso de este aspecto (con un estudio comparativo que incluya entre otras cosas el uso de la digresión y la amplificación en uno y otro género) como una manera de profundizar nuestro conocimiento de la relación entre el sermón y el comentario, y la de ambos con la literatura. Pues, a medida que avancemos en la comprensión de estos métodos exegéticos y estos rasgos formales y estructurales, mayor será nuestra percepción de su decisiva trascendencia y de su productividad, todavía vigente, en la literatura.

${ }^{8} \mathrm{El}$ predicador anuncia solemnemente que ha imprimido una nueva "forma castellana perpetua" a las oraciones fúnebres o panegíricos. Francis Cerdan explica en qué consiste esa novedad: "Paravicino se atrevió a hacer oraciones fúnebres sin tema y sin las divisiones internas que tenían los sermones" $(223, \mathrm{n} .11)$ Por supuesto, Fray Hortensio representaba también el paradigma del estilo culto -el de la nueva poesía - en la oratoria sagrada de su tiempo.

${ }^{9}$ Hay aquí, naturalmente, como en muchos otros lugares de la obra de Paravicino, claros ecos de la polémica anticulterana. 


\section{Bibliografía}

Alonso, Dámaso, "Predicadores ensonetados", en Del siglo de oro a este siglo de siglas, Madrid, Gredos, 1962, pp. 95-104.

Blanco, Mercedes, "La oralidad en las justas poéticas", Edad de Oro, VII, 1988, pp. 33-47.

CERdAN, Francis, "El sermón barroco: un caso de literatura oral", Edad de Oro, VII, 1988, pp. 59-68.

- - Paravicino, Fray Hortensio, Sermones cortesanos, ed. de Francis Cerdan, Madrid, Castalia/Comunidad de Madrid, 1994.

EGiDo, Aurora, "Literatura efímera: oralidad y escritura en los certámenes y academias de los Siglos de Oro”, Edad de Oro, VII, 1988, pp. 69-87.

LeCoy DE la MARChe, Albert y Jacques Berloz, Le rire du prédicateur. Récits facétieux du Moyen Âge, traducción francesa de A. Lecoy de la Marche, presentación, notas y anexos de Jacques Berlioz, París, Brepols, 1992.

Olmedo, Félix G., "Santa Teresa de Jesús y los predicadores del Siglo de Oro", Boletín de la Real Academia de la Historia, Madrid, LXXXIV, 1924, pp. 165-175 y 280-295.

Ormaza, José de, Censura de la elocuencia [Zaragoza, 1648], introducción de Giuseppina Ledda y texto de Giuseppina Ledda y Vittoria Stagno, Madrid, El Crotalón, 1985.

Orozco DíAz, Emilio, "Sobre la teatralización del templo y la función religiosa en el barroco: el predicador y el comediante", Cuadernos para investigación de la literatura hispánica, Fundación universitaria española, Seminario Menéndez Pelayo, Madrid, núm. 2-3, 1980, pp. 171-188.

-PÉrez de Ledesma, Gonzalo (ver José de Ormaza).

Rico, Francisco, Predicación y literatura en la España medieval, Cádiz, UNED, 1977. 